\title{
PROPHYLACTIC ANTICRYPTOSPORIDIAL ACTIVITY OF ATORVASTATIN VERSUS NITAZOXANIDE ON EXPERIMENTALLY INFECTED IMMUNOSUPPRESSED MURINE MODELS
}

\section{By}

ASMAA M. FAROUK AL-GHANDOUR ${ }^{1 *}$, ASMAA MOHAMMED YOUSEF ${ }^{1}$, RASHA M. S. M. MOHAMED ${ }^{2}$, AL-SAYED M. TEALEB ${ }^{5}$, HYTHAM K. AHMED ${ }^{4}$, HANAA A. ATWA ${ }^{3}$ and TAHANI ISMAIL FARAG ${ }^{1}$

Departments of Medical Parasitology ${ }^{1}$, Clinical Pharmacology ${ }^{2}$, Pathology $^{3}$, Clinical Pathology ${ }^{4}$, Faculty of Medicine, Zagazig University, Zagazig, and Department of Pathology ${ }^{5}$, Al-Azhar University, Cairo, Egypt ( ${ }^{\star}$ Correspondence: amfahmy@zu.edu.eg)

\section{Abstract}

This study investigated the possible prophylactic and curative role of Atorvastatin (ATV) in treatment of cryptosporidiosis in immunosuppressed cases. Immunosuppression was done using oral dexamethasone $(0.25 \mu \mathrm{g} / \mathrm{g} /$ day $)$ for 14 days before infection till last scarification. The study included 150 immunosuppressed mice in 5 major groups (N=30): G1: Normal control group, G2: Infected control group, G3: ATV (40mg/kg/day), G4: Nitazoxanide (NTZ; 500$\mathrm{mg} / \mathrm{kg} /$ day), G5: combination group. Each one was divided into 3 subgroups of 10 mice each: prophylaxis ones received drug daily for 5 consecutive days before infection only, $1^{\text {st }}$ and $2^{\text {nd }}$ therapeutic dose groups: mice received the drug for 1 week and 2 weeks after prophylaxis and infection, respectively. Assessment was done parasitological by formol-ether concentration and Modified Ziehl-Neelsen staining of stool pellets gathered weekly, immunological by serum IFN-y levels and histopathological by haematoxyline and eosin staining to determine the drug regimens and parasite impacts on tissues.

The results showed a significant reduction in inflammatory changes of ileum, stomach and liver histopathology and in oocysts shed on the $7^{\text {th }}$ day post infection (PI) by $62.08 \%, 40.55 \%$ $\& 71.78 \%$, on the $14^{\text {th }}$ day (PI) by $78.53 \%, 53.4 \%, 87.43 \% \& 90.41 \%, 57.21 \%, 94.71 \%$ on $21^{\text {st }}$ day (PI) in all treated groups respectively, compared to infected untreated control ones. Sera IFN- $\gamma$ levels showed significant increase in combination followed by ATV prophylactic drug regimens compared to NTZ alone or infected control ones. Combined ATV and NTZ prophylaxis gave a good synergistic anticryptosporidial efficacy in immunosuppressed mice. Key words: Cryptosporidium, Atorvastatin, Prophylaxis, Nitazoxanide combination, immunosuppressed.

\section{Introduction}

Cryptosporidium species are well recognized as corporate causes of both water- and food-borne outbreaks of diarrheal illness around the world (Ryan et al, 2018). Livestock (mainly cattle) and wildlife (e.g. deer) were found to be pertinent donors to zoonotic Cryptosporidium oocysts in recreational and drinking water supplies. Exploring hostparasite relationship to better understand cryptosporidiosis and its defense within the host is a requirement to advance its stratagems for prophylaxis and treatment. Modern advances in the genetic diagnosis of Cryptosporidium combined with new in vitro and in vivo models gave a better awareness of these relations (Widmer et al, 2020). Pollok et al. (2001) reported that immunological control of cryptosporidial infection in mice depended mainly on CD4 $+\mathrm{T}$ cells and gamma interferon (IFN- $\gamma$ ) production.

A wide range of techniques are used to investigate the immune response to $C$. parvum infection and the host-parasite relationship. Studies on murine models face certain obstacles, as in discrepancy with neonatal models, adult immunocompetent mice are hardly infected with $C$. parvum and there was thus no suitable adult mouse model to study Cryptosporidium infection. Sateriale et al. (2019) isolated a line of Cryptosporidium tyzzeri, a species that naturally colonizes the small intestine of mice and is also genetically tractable with CRISPR/Cas9. With this new murine model and many transgenic mouse lines, it was easy to prove that inter- 
feron $\gamma$ is a key cytokine and the significant role of $\mathrm{T}$ cells as a backbone in the fight against infection in adult mice. Moreover, this study confirmed that primary infection gives protection against a homologous challenge, redirecting our target towards evolving a vaccine that prevents or prohibits the severity of cryptosporidiosis and to trail the progression of the Cryptosporidium life cycle controlled by stage-specific agents, such as promoters those are active during sexual differentiation and oocyst formation (Wilke et al, 2019).

All plastid-associated metabolic pathways in Cryptosporidium parasite as one of the apicomplexan family e.g.; Methylerythritol phosphate pathway- are missing; as they lost their apicoplast during development (Abrahamsen et al, 2004; Xu et al, 2004).

Artz et al. (2008) reported that Cryptosporidium spp. genome has an entree to isoprenoid precursors, by salvaging isoprenoids derived from isopentenyl-5- pyrophosphate (IPP) or other short to-medium-chain isoprenoids from the host as it has three prenyl synthases. A cell-based high-throughput screening (HTS) for anti-cryptosporidial agents; screening the NIH Clinical Collections libraries reported that statins were identified as a hopeful principal candidate with effective capability in inhibiting growth of Cryptosporidium spp.

Atorvastatin (ATV) was first approved in the UK as a synthetic statin that subsists in its active hydroxy-acid formula with pyrole based ring assembly (Davidson, 2002). HMG-CoA reductase inhibition held by ATV and its family in the host liver is well tolerated in man; this made the statins an excellent applicant for repurposing as an anti-cryptosporidial agent.

Nitazoxanide (NTZ, Alinia; Romark Laboratories L.C., Tampa Florida, USA); licensed by the U.S. Food and Drug Administration (FDA) for the treatment of cryptosporidiosis in immune-competent, but unfortunately it gave unsatisfactory effects in immunosuppressed even after several week
$(100 \mathrm{mg} / \mathrm{kg} /$ day) therapy confirmed by nested-PCR technique (Atia et al, 2016).

No available information concerning the efficacy of HMG-CoA reductase inhibitors and its combination with FDA-approved anti-parasitic Nitazoxanide drugs prophylaxis on liver tissue and biliary tract in cryptosporidiosis of immunosuppressed patients (Taha et al, 2017).

The work aimed to assess the prophylactic efficacy and therapeutic of Atorvastatin (ATV) versus high dose Nitazoxanide and their dual role on cryptosporidiosis in experimentally immunosuppressed mice.

\section{Materials and Methods}

Mice and immunosuppression: One hundred and fifty laboratory-bred, clean, male, Swiss albino mice, 10 weeks old and weighing 25-30g, were used. They were kept in the animal house and white wood chips for bedding. At Parasitology Department, Zagazig University Hospital; mice were fed by a commercial complete food mixture and previously boiled-tap water for drinking, and maintained under controlled environment with average temperature $\left(25 \pm 2^{\circ} \mathrm{C}\right)$ and standard light-dark cycle throughout the experimental period. This experiment was carried out according to the Clinical and Laboratory Standards Institute (CLSI) guide-lines, and was approved by the ethical committee of Zagazig University Hospitals.

All mice were immunosuppressed by oral administration of Dexamethasone at a dose of $0.25 \mu \mathrm{g} / \mathrm{g} /$ day for 14 days before infection; Dexazone $(0.5 \mathrm{mg})$ orally (Kahira Pharmaceuticals and Chemical Industries Company, Egypt). The mice continued to receive dexamethasone at the same dose throughout the study (Rehg et al, 1988).

Mice were divided into five groups (G), 30 mice each; G1 was non-infected-non treated (negative control), G2 was infected-non treated (positive control), G3 was treated by Atorvastatin alone (ATV $40 \mathrm{mg} / \mathrm{kg} /$ day), G4 was received NTZ (500 $\mathrm{mg} / \mathrm{kg} /$ day-bid-); (drug control), and G5 was treated by Atorvastatin combination (ATV $40 \mathrm{mg} / \mathrm{kg} / \mathrm{day}+$ 
NTZ 500mg/kg/day-bid-).

Prophylaxis, Infection \& therapy: Prophylaxis was done for 5 days before infection for the last 3 groups; either by Atorvastatin alone (ATV $40 \mathrm{mg} / \mathrm{kg} /$ day) or NTZ (500 $\mathrm{mg} / \mathrm{kg}$ /day-bid-) or their combination (ATV $40 \mathrm{mg} / \mathrm{kg} /$ day + NTZ 500mg/kg/day-bid-) respectively. Infection was done by inoculation of G2, infected control group $+\mathrm{G} 3, \mathrm{G} 4$, \& G5 prophylactically treated groups of mice intraoesophagealy with $0.1 \mathrm{ml}$ of Cryptosporidium oocysts inoculum $\left(3 \times 10^{3}\right.$ oocysts $/ \mathrm{ml}$ ) (Benamrouz et al, 2012).

Cryptosporidium oocysts were obtained from Pediatric Oncology Department diarrheic children. The stool samples were collected in sterile clean stool cups without contaminated water or urine. After collection of stool samples, oocysts were purified (Arrowood and Donaldson 1996). Purified oocysts were kept in $2.5 \%$ potassium dichromate solution and stored at $4{ }^{\circ} \mathrm{C}$ until required. Infective inoculum was prepared and the number of oocysts in the concentrated stock inoculum was counted to determine the inoculum per mouse (Reese et al, 1982). Mice feces were examined daily for oocysts recovery to confirm infection, which was recovered after 3-5 days. Fecal pellets were collected and parasitologically examined using formol-ether concentration and the Modified Ziehl-Neelsen stain (Casemore et $a l, 1985)$ for oocysts and ten mice from each group were sacrificed a week after infection to evaluate the prophylaxis effect.

At the $7^{\text {th }} \& 14^{\text {th }}$ days post-infection (P.I.), continued treatment Post-infection for 2 booster doses at 1 st and 2 nd weeks respectively after infection for the last 3 groups (G3, G4 \& G5) in 5 successive days; postprophylactic doses, either by Atorvastatin alone (ATV $40 \mathrm{mg} / \mathrm{kg} /$ day) or Nitazoxanide alone (NTZ $500 \mathrm{mg} / \mathrm{kg} /$ day-bid-) or combination (ATV $40 \mathrm{mg} / \mathrm{kg} /$ day+ NTZ 500mg/ $\mathrm{kg}$ /day) respectively. On the $14^{\text {th }} \& 21^{\text {st }}$ days PI, ten mice from each group were sacrificed to evaluate the effect of treatment after $1^{\text {st }} \&$ $2^{\text {nd }}$ doses. At the end of treatment, small in- testine from each sacrificed mouse was divided into two parts; one for the histopathological study, and the second for measuring the antioxidant activity.

Drugs: Atorvastatin (Ator) 20mg tabs was smashed, dissolved freshly in distilled water and given orally using oesophageal tube at a dose of $40 \mathrm{mg} / \mathrm{kg} /$ day $(200 \mathrm{ml} / \mathrm{mouse})$ for 5 consecutive days (Penna-Coutinho et al, 2011). Nitazoxanide (Nanazoxid): a broadspectrum 5-nitrothia-zole was used as a drug control. $500 \mathrm{mg}$ tablets were used. Tablets were smashed, dissolved in distilled water and given to orally mice using oesophageal tube in a dose of $500 \mathrm{mg} / \mathrm{kg}$ body weight $(200 \mu 1 /$ mouse) for five consecutive days (Abd ElAziz et al, 2014). The doses were calculated by extrapolation of human therapeutic doses to animal doses (Paget and Barnes 1965).

Parasitological drug evaluation: After administration of drugs, fecal pellets were collected from infected mice at $7^{\text {th }}, 14^{\text {th }} \& 21^{\text {th }}$ PI examined using formol-ether concentration and the Modified Ziehl-Neelsen stain to count the number of Cryptosporidium oocysts (Casemore et al, 1985). The number of parasites was expressed per gram of feces (Benamrouz et al, 2012).

The efficacy percentage of each drug was calculated using the equation: Efficacy (\%) $=$ mean value of infected untreated group mean value of infected treated group x $100 /$ mean value of infected untreated group (Hosking et al, 1996).

Histopathological drug evaluation: The ileocecal junction, stomach and liver tissues were excised, and opened longitudinally, oriented on a filter paper and fixed in $10 \%$ formalin. After fixation, the tissues were processed for paraffin embedding. Sections of $4 \mu \mathrm{m}$ thickness were stained with haematoxyline and eosin (H\&E) stain and examined for pathological changes (Drury and Wallington, 1980).

Determination of interferon gamma (IFN$\gamma)$ levels in mice sera: Blood samples were with-drawn at the scarification time in plain 
tubes. Sera were separated by left blood at room temperature for 30 minutes, centrifuged at $3000 \mathrm{rpm}$ for $15 \mathrm{~min}$. aliquoted and stored at $-20^{\circ} \mathrm{C}$. IFN- $\gamma$ concentrations were assayed by double-sandwich ELISA kit after the manufacturer's instructions (Bioneovan Co, Ltd, Beijing, China). Optical density values were measured at $450 \mathrm{~nm} \& 630 \mathrm{~nm}$ filters. Concentrations of IFN- $\gamma$ were determined from standard curve with $3 \mathrm{pg} / \mathrm{ml}$ $200 \mathrm{pg} / \mathrm{ml}$ assay ranges.

Statistical analysis: Data were presented as mean and SD and determined by two-way ANOVA, followed by a post hoc Bonferroni test, one-way ANOVA with Tukey's Multiple Comparison Test, unpaired Student's ttest for selected pairs of data using Graph Pad Prism version 5 (Graph Pad Software). $P$ values $<0.05$ were considered significant, Significant $P$ value $<0.05$ and highly significant $\mathrm{P}<0.001$ (Peat and Barton, 2005).

Ethical consideration: The study was conformed to the Guide for the Care and Use of Laboratory Animals published by the US NIH (No. 85-23, revised 2011)

\section{Results}

Oocysts reduction: $C$. parvum oocysts were counted in stool pellets of immunosuppressed mice after 5-7 days PI ( $7^{\text {th }}$ day), then 5-7 days of $1^{\text {st }}$ dose therapy ( $14^{\text {th }}$ day), and lastly after 7 days of $2^{\text {nd }}$ dose therapy $\left(21^{\text {st }}\right.$ day). Atorvastatin (ATV $40 \mathrm{mg} / \mathrm{kg} /$ day) reduced Cryptosporidium oocysts number in infected mice when used as prophylaxis alone or prophylaxis followed by treatment after infection compared to NTZ $(500 \mathrm{mg} /$ $\mathrm{kg}$ /day) alone and their combination dual efficacy. Oocysts in infected control mice (G2) decreased (G2a) from (185700土 $45114.12)$ on $7^{\text {th }}$ day to $(177600 \pm 1502.223)$ in $(\mathrm{G} 2 \mathrm{c})$ on $21^{\text {st }}$ day P.I. Prophylactic treatment of infected mice by ATV40 in (G3a) significantly reduced the mean Cryptosporidium oocysts clearance $(\mathrm{P}<0.0001)$ with (62.08\%) efficacy, while dual PX (G5a) (ATV40+ NTZ500) was (71.78\%) compared to NTZ prophylaxis alone (G4a) was $(40.55 \%)$. In the $1^{\text {st }}$ dose therapy after PX
(14 ${ }^{\text {th }}$ day P.I), ATV40 in (G3b) had (78.53\%) efficacy that reached $(90.41 \%)$ in $2^{\text {nd }}$ week therapy after PX (G3c) compared to $(53.4 \%) \&(57.21 \%)$ in NTZ alone (G4b, c, respectively). The best efficacy was by dual therapy after PX (ATV40+NTZ 500), to $(87.43 \%)$ at $14^{\text {th }}$ day PI (G5b), and (94.71\%) at $21^{\text {st }}$ day PI. (G5c).

Comparison between each regimen in the three prophylactic period of $1^{\text {st }} \& 2^{\text {nd }}$ booster therapeutic doses and corresponding infected control one (Fig.1) showed very high significant reduction of oocysts counts in all prophylactic treated groups as compared to positively infected ones, with significant difference between oocyst reduction of NTZ \& ATV groups in prophylaxis and $1^{\text {st }}$ week therapy after that only.

Histopathological examination of ileal mucosa of Cryptosporidium infected mice revealed profound histopathological changes in the intestinal mucosa as a result of infection with Cryptosporidium oocysts in the form of villous atrophy, inflammatory cellular infiltrate. Some cases revealed nuclear changes and dysplasia (increased Nuclear/cytoplasmic ratio, pleomorphism, prominent nucleoli, and frequent mitotic figures) with intra epithelial inflammatory cells with eosinophils. ATV-treated group showed mild inflammatory cellular infiltrate or nearly normal ileal tissue in comparison to infected untreated group or drug control therapy while, the combination regimens showed normal appearance with minimal inflammatory cells and pathological changes.

Histopathological examination of ileum showed mild to moderate inflammation, edema, low grade dysplasia, tissue necrosis and sloughing as well as oocysts, but treated ones showed marked inflammation and dysplasia improvement. ATV-treated group showed mild inflammatory cellular infiltrate or normal gastric tissue as compared to infected untreated group or drug control therapy while, the combined regimens had better outcome as compared to ATV treated ones after prophylaxis with minimal inflammato- 
ry cells and pathological changes.

Histopathological examination of liver tissue showed infiltration by oocysts with inflammatory cells within portal tract and hepatic lobules, associated with dilated sinusoids, vacuolated cytoplasm, focal necrosis, apoptosis, and bile duct proliferation were focally in few cases. Large cell dysplasia occurred in some cases. The inflammation ranged from mild, moderate to severe inflammation. ATV alone and combined regimens showed mild inflammation to normal liver tissue architecture. IFN- $\gamma$ levels were highly significantly increased after Atorvastatin prophylaxis (G3a: ATV40-PX) $\left(7^{\text {th }}\right.$ day P.I) reached $(21 \pm 0.95)$ compared to the infected G2a $(15.7 \pm 0.87)(\mathrm{P}<0.0001)$ with $\mathrm{T}$ test (13.01). In G3b, after prophylaxis, infection and $1^{\text {st }}$ dose therapy by (ATV40) $\left(14^{\text {th }}\right.$ day P.I), IFN- $\gamma$ level was more significantly increased to $(72.9 \pm 0.89)$ compared to infected G2b $(\mathrm{P}<0.0001)(14.8 \pm 0.80)$ with T-test (153.5). G3c after prophylaxis and $2^{\text {nd }}$ dose therapy with (ATV40; $21^{\text {st }}$ day P.I), IFN- $\gamma$ level was significant highly increased to (77.9 \pm 0.89$)$ compared to $\mathrm{G} 2 \mathrm{c}(\mathrm{P}<0.0001)$ (13.8 \pm 0.80$)$ with T-test (162.3) (Fig. 2).

At $14^{\text {th }}$ day PI, mean IFN- $\gamma$ level in (G4a) NTZ prophylaxis group was (16 \pm 1.02$)$ without significant $(\mathrm{P}>0.05)$ and $\mathrm{T}$-test $(0.7076)$ compared to infected $\mathrm{G} 2 \mathrm{a}(15.7 \pm 0.87)$. In $\mathrm{G} 4 \mathrm{~b}$, after prophylaxis \& $1^{\text {st }}$ week NTZ therapy $\left(21^{\text {st }}\right.$ day PI), mean IFN- $\gamma$ level to (19.3$\pm 0.63)$ with a high significant $(\mathrm{P}<0.0001)$ compared to G2b and T-test (13.97), but in subsequent $2^{\text {nd }}$ week therapy G4c $\left(28^{\text {th }}\right.$ day PI) reached $(24.2 \pm 1.10)$ with a high significant $(\mathrm{P}<0.0001)$ compared to infected G2c and T-test (24.36). In combined ATV40 + NTZ 500, IFN- $\gamma$ levels in prophylaxis G5a showed a significant increase $(24.2 \pm 1.08)$ compared to infected $\mathrm{G} 2 \mathrm{a}(\mathrm{P}<0.0001)$ with T-test (19.38). In G5b after prophylaxis and $1^{\text {st }}$ dose therapy, IFN- $\gamma$ levels showed more significant increase $(47.3 \pm-0.91)$ compared to infected $\mathrm{G} 2 \mathrm{~b}(\mathrm{P}<0.0001)$ with $\mathrm{T}$-test (84.82).

In $2^{\text {nd }}$ dose after PX IFN- $\gamma$ levels reached
$(81.4 \pm 0.85)$ with highest significant increase (P <0.0001) compared to $\mathrm{G} 2 \mathrm{c}$ with $\mathrm{T}$-test (175) (Fig. 2).

\section{Discussion}

Watery diarrhea and malabsorption were symptoms linked to sodium malabsorption, electrogenic chloride secretion, and increased intestinal permeability associated with cryptosporidiosis (Zhang et al, 2000). Some neuropeptides e.g. substance $\mathrm{P}$ and host immune response itself were the main sponsors for these effects (Pantenburg et al, 2008). Checkley et al. (2015) thought that ileitis by cryptosporidiosis is the main contributor of the bad impacts on its host overall health with the impaired absorption and copious secretions indorsing diarrheal disease, most aggravated in children and immunosuppressed patients. They concluded that the imperative anticryptosporidial target that restores the small intestinal villi integrity reflected considerable impact on human's health.

Nitazoxanide (NTZ), a nitrothiazole salicylate derivative, absorbed from the gastrointestinal tract advisable during taking meal, is active on bacteria as Helicobacter pylori and a broad spectrum of helminths as Taenia saginata, Hymenolepis nana, Fasciola hepatica and protozoa as Isospora belli, Entamoeba histolytica, Giardia lamblia and Enterocytozoon bieneusi (Rossignol and Maisonneuve, 1984; McVay and Rolfe, 2000; Bicart-See et al, 2000).

Nitazoxanide is the only proven antiparasitic treatment for cryptosporidiosis by FDA, despite its low efficacy in immunocompromised cases, which restricted choices treatment grants a foremost public health contest assuming the significant load of disease in immunosuppressed (Sparks et al, 2015 and Atia et al, 2016).

Li et al. (2003) in an immunosuppressed rat was studied the long-lasting anti-cryptosporidial activity of nitazoxanide in comparison with sinefungin (SNF) and paromomycin (PRM) showed that NTZ at either $50 \mathrm{mg} /$ $\mathrm{kg} / \mathrm{day}, 100 \mathrm{mg} / \mathrm{kg} / \mathrm{day}$ or $200 \mathrm{mg} / \mathrm{kg} /$ day, in seven days duration gave a dose-dependent 
reduction in oocyst shedding as with SNF $(10 \mathrm{mg} / \mathrm{kg} /$ day) and PRM $(100 \mathrm{mg} / \mathrm{kg} /$ day $)$. The stoppage of SNF or PRM $100 \mathrm{mg} / \mathrm{kg} /$ day therapy led to early relapse of oocyst clearance that returned to pre-treatment levels in 2-4 days, with unchanged data after seven days stoppage of NTZ therapy, recommended more assessment of NTZ activity on sequestered C. parvum for longer durations in immunosuppressed models.

Others preferred combined therapies to eradicate cryptosporidiosis especially in immunocompromised \& HIV patients (Giacometti et al, 2000). There was sustained attention to improve therapies for this infection. Huwiler and Pfeilschifter (2009) showed the capability of lipid species as signaling molecules controlling the magnitude of cellular responses as cell growth, apoptosis and inflammatory reactions. Statins are well-known as cholesterol biosynthesis (steroid biosynthesis) inhibitors in humans by 3-hydroxy-3methyl-glutaryl-coenzyme A (HMG-CoA reductase) inhibition. This enzyme has a beneficial role in regulating the mevalonate pathway, which produced cholesterol beside heme-A, coenzyme Q10 and isoprenylated proteins (Callegari et al, 2010; Taha et al, 2017). Statins occluded the intracellular transfer when stopped formation of isoprenoid (IPP) intermediates (Zhou and Liao, 2009).

Dinesh et al. (2014) studied the Atorvastatin and Simvastatin anti-leishmanial activity and proved their mechanisms via inhibition of HMG CoA reductase enzyme.

Cryptosporidia with different genomes e.g. $C$. parvum and $C$. hominis genomes as members of the apicomplexan parasites are characterized by utilization of isoprenoids derived from IPP and dimethyl-allyl pyrophosphate (DMAPP) in one or more pathways as detected by the bioinformatics analysis of Cryptosporidium spp. genomes, despite we couldn't confirm their ability to synthesis their own IPP or DMAPP independent on their host (Bessoff et al, 2013). In accordance with this study results, prophylactic dose that preceded experi- mental cryptosporidial infection and the two booster therapeutic doses of Atorvastatin $(40 \mathrm{mg} / \mathrm{kg})$ had enhanced a high significant oocyst reduction $(62.08 \%)$ when used alone or in combined regimen (71.78\%) and when the drug control group by Nitazoxanide $(500 \mathrm{mg} / \mathrm{kg})$ used alone $(40.55 \%)$ as compared with the infected control groups with duration-dependent increase in clearance of oocysts from stools. This agreed with Taha et al. (2017) who proved the therapeutic role of atorvastatin in cryptosporidiosis challenged infection in immunocompromised rats. They tested the therapeutic efficacy of 2 different doses of ATV (20 \& 40mg/ $\mathrm{kg}$ ) alone and when combined with NTZ (1000 $\mathrm{mg} / \mathrm{kg}$ ) in treatment of cryptosporidiosis experimental infection. The study showed valuable oocyst reduction in (ATV+NTZ) combination as compared with infected, and drug controls and with that of 40mg \& 20 mg ATV drug regimens at the $21^{\text {st }}$ day PI; respectively. Basyoni et al. (2018) found that dose-dependent efficacy of ATV (20-40 $\mathrm{mg} / \mathrm{kg}$ ) either alone or in combination with Metronidazole $(10 \mathrm{mg} / \mathrm{kg})$ in experimentally Blastocystis-infected mice caused the highest reductions in Blastocystis shedding.

Statins induced inhibition of cysteine protease and protected endothelial barrier integrity (Mirza et al, 2012). Abdin et al. (2012) proved the valuable role of statins as antioxidants and anti-inflammatory agents beside their cholesterol-lowering activity.

The present results agreed with Soliman and Ibrahim (2005) who interpreted the exaggerated apoptotic changes in Cryptosporidium infected groups and the exposure to combination therapy of ATV $(40 \mathrm{mg} / \mathrm{kg})$ and NTZ $(500 \mathrm{mg} / \mathrm{kg})$ by having the advantage of dual effects of ATV in healing epithelial tissues and targeting Cryptosporidium.

Higher doses of HMG-CoA reductase inhibitors were tested with antimalarial drugs (Wong and Davis, 2009); on Babesia divergens (Grellier et al, 1994), Plasmodium falciparum (Pradines et al, 2007), and also on Toxoplasma gondii growth (Cortez et al, 
2009) in vitro and gave valuable inhibitory effects on these coccidian protozoa. Nevertheless, in-vivo studies showed that statins inhibited the growth of both Trypanosoma procyclic and epimastigote forms (Coppens et al, 1995), and increased animals' survival via inhibition of proliferation of more than $50 \%$ of Toxoplasma gondii in macrophages in a dose-dependent manner (Nishikawa et al, 2011; Li et al, 2013). Also, Atorvastatin showed tegumental modifications in $S$. haematobium adults with significant reduction in its burden and egg load (Soliman and Ibrahim, 2005). Zhao et al. (2006) found direct and indirect antioxidant capabilities of statins to remove aged LDL, reduce reactive oxygen species and good effects in cardi-ovascular diseases due to lipid lowering activity.

In this study, stained sections showed different inflammation degrees, and was classified based on cellular infiltration heaviness and presence of lymphocytic aggregation into mild, moderate and severe (Dieleman et al, 1998). Decreased ratio of villous height to crypt length, goblet cell depletion, lamina propria showed oedema with diffuse loss of brush border microvillous surface area. Atorvastatin prophylaxis resulted in upgrading partial improvement in such changes compared to drug control, with marked improvement in combined prophylactic therapy with mild inflammatory changes approaching to normal gastric and ileal mucosa due to partial healing and restoration of the villous architecture. This was agreed with Taha et al. (2017) who found good improvement of combined treated groups without prophylaxis with 20 or $40 \mathrm{mg} / \mathrm{kg} /$ day doses of ATV combined with NTZ $(1000 \mathrm{mg} / \mathrm{kg} /$ day $)$. In this study, moderate gastritis of infected untreated mice with moderate inflammatory infiltration and edema occur- red. Combined regimens showed remarkable improvement with normal gastric tissue, and ATV alone showed mild gastritis. Sections of NTZ treated group didn't show a significant improvement with persistent moderate gastritis. Also, infected liver tissue in NTZ and ATV treated groups showed portal tract expansion by fibrosis, moderate inflammatory infiltrate and bile duct proliferation. Also, combined treated group after PX showed mild inflammatory cellular infiltrate within portal tract and hepatocytes markedly infiltrated by inflammatory cells with dilated sinusoids.

In this study, immunosuppressed infected mice shed oocysts in stool with significant serum IFN- $\gamma$ reduced levels compared to normal control non-infected one. This agreed with Beardsley et al. (2018) who found that dexamethasone reduced the body production of IFN- $\gamma$ led to worse cryptococcal meningitis and high mortality. The IFN- $\gamma$ is one of the key body defense mechanisms against cryptosporidiosis (Gomez et al, 1996; Lacroix et al, 2001). Hayward et al. (2000) reported that IFN- $\gamma$ protected immunodeficient mice from death from cryptosporidiosis.

In the present experiment, immunosuppressed mice experienced significant time depeendent decrease in the number of shed oocysts in stool pellets with significant time dependent increase in IFN- $\gamma$ compared to NTZ treated one. This agreed with Bessoff et al. (2013) who found potent inhibitory action (HMG-CoA) reductase inhibitor (itavastatin) on $C$. parvum growth. Also, Amadi et al. (2009) found that NTZ couldn't eradicate Cryptosporidium infection in children with HIV immunosuppression. Anti-cryptosporidial effect of NTZ depended on IFN- $\gamma$ using an anti-IFN-gamma conditioned SCID mouse model (Theodos et al, 1998). Combined prophylaxis and treatment of immunosuppressed mice with atorvastatin and NTZ exhibited good synergistic prophylactic effect on eradication of oocytes, with the highest reduction percentage than either one alone. This agreed with Taha et al. (2017) who found synergistic role of atorv-astatin \& NTZ in treating Cryptosporidium in immunosuppressed mice that showed significant time dependent increase in IFN- $\gamma$ serum to normal level. Alber et al. (2006) found that atorvastatin has anti-inflammatory effect in atherosclerosis without affecting IFN- 
$\gamma$ level, and Yi et al. (2008) added that atorvastatin reduced IFN- $\gamma$ levels

\section{Conclusion}

Atorvastatin and high dose NTZ were used as prophylactic regimens to ameliorate the immune status and severity of cryptosporidiosis on immunosuppressed or lower heavy oocysts shedding. Atorvastatin gave progressive decline in oocyst excretion after PX with subsequent therapeutic dose that was more aggravated by synergistic combined with high prophylaxis Nitazoxanide dose. Molecular or ultrastructure study to clarify the effective prophylactic dose regimen is ongoing and will be published in due time.

Conflict of interest: The authors declared that they neither have any interest nor received fund.

\section{References}

Abd El-Aziz, TM, El-Beih, NM, Soufy, H, Nasr, SM, Khalil, FAM, et al, 2014: Effect of Egyptian propolis on lipid profile and oxidative status in comparison with Nitazoxanide in immunosuppressed rats infected with Cryptosporidium spp. Global Vet. 13, 1:17e27

Abdin, AA, Abd El-Halim, MS, Hedeya, SE, El-Saadany, AAE, 2012: Molecular and cellular pharmacology effect of atorvastatin with or without prednisolone on Freud's adjuvant induced-arthritis in rats. Euro J. Pharmacol. 676, 15:34-40

Abrahamsen, MS, Templeton, TJ, Enomoto, S, Abrahante, JE, Zhu, G, et al, 2004: Complete genome sequence of the apicomplexan, Cryptosporidium parvum. Science 304:e441-5.

Alber, HF, Frick, M, Suessenbacher, A, Doerler, J, Schirmer, M, et al, 2006: Effect of atorvastatin on circulating proinflammatory $\mathrm{T}$ lymphocyte subsets and soluble CD40 ligand in patients with stable coronary artery disease, a randomized, placebo-controlled study. Am. Heart J. 151, 1:139-e1.

Amadi, B, Mwiya, M, Sianongo, S, Payne, L, Watuka, A, et al, 2009: High dose prolonged treatment with nitazoxanide is not effective for cryptosporidiosis in HIV positive Zambian children: A randomized controlled trial. BMC Infect. Dis. 9, 1:195.

Arrowood, MJ, Donaldson, KIY, 1996: Improved purification methods for calf-derived Cryptosporidium parvum oocysts using discontinuous sucrose and cesium chloride gradients. J. Eukary. Microbiol. 43, 5:S89-91.

Artz, JD, Dunford, J, Arrowood, M, Dong, A, Chruszcz, M, et al, 2008: Targeting a uniquely non-specific prenyl synthase with bisphosphonates to combat cryptosporidiosis. Chem. Biol. 15:e1296-306

Atia, MM, Abdul Fattah, MM, Abdel Rahman, HA, Mohammed, FA, Al Ghandour, AM, 2016: Assessing the efficacy of nitazoxanide in treatment of cryptosporidiosis using PCR examination. J. Egypt. Soc. Parasitol. 46, 3:683-92

Basyoni, MMA, Fouad, SA, Amer, AF, Ismail, DI, 2018: Atorvastatin: In-vivo synergy with metronidazole as anti-Blastocystis Therapy. Kor. Soc. Parasitol. Trop. Med. 56, 2:105-12.

Beardsley, J, Nhat, LTH, Kibengo, FM, Tung, NL, Binh, TQ, et al, 2018: Do intracerebral cytokine responses explain the harmful effects of dexamethasone in HIV-associated cryptococcal meningitis?. Clin. Infect. Dis. 68, 9:23-8.

Benamrouz, S, Guyot, K, Gazzola, S, Mouray, A, Chassat, T, et al, 2012: Cryptosporidium parvum infection in SCID mice infected with only one oocyst: qPCR assessment of parasite replication in tissues and development of digestive cancer. PLoS One 7, 12:e51232.

Dieleman, LA, Palmen, MJHJ, Akol, H, Bloemena, E, Pen, AS, et al, 1998: Chronic experimental colitis induced by dextran sulphate sodium (DSS) is characterized by Th1 and Th2 cytokines. Clin. Exp. Immunol. 114:385-91.

Benamrouz S, Guyot K, Gazzola S, Mouray A, Chassat T, et al, 2012: Cryptosporidium parvum infection in SCID mice infected with only one oocyst: qPCR assessment of parasite replication in tissues and development of digestive cancer. PLoS ONE 7, 12:e51232

Bessoff, K, Sateriale, A, Lee, KK, Huston, C D, 2013: Drug repurposing screen reveals FDAapproved inhibitors of human HMG-CoA reductase and isoprenoid synthesis that block Cryptosporidium parvum growth. Antimicro. Agen. chChemother. 57, 4:1804-14.

Bicart-Sée, A, Massip, P, Linas, MD, Datry, A, 2000: Successful treatment with nitazoxanide of Enterocytozoon bieneusi microsporidiosis in a patient with AIDS. Antimicro. Agen. Chemother. $44,1: 167-8$.

Callegari, S, McKinnon, RA, Andrews, S, de Barros, MA, 2010: Atorvastatin-induced cell toxicity in yeast is linked to disruption of protein isoprenylation. FEMS Yeast Res. 10, 2: 188-98. 
Casemore, DP, Armstrong, M, Sands, RL, 1985: Laboratory diagnosis of cryptosporidiosis. J. Clin. Pathol. 38:1337-41.

Checkley, W, White, Jr AC, Jaganath, D, Arrowood, MJ, Chalmers, RM, et al, 2015: A review of global burden, novel diagnostics, therapeutics, and vaccine targets for Cryptosporidium. Lancet Infect. Dis. 15, 1:85-94

Coppens, I, Bastin, P, Levade, T, Courtoy, P J, 1995: Activity, pharmacological inhibition \& biological regulation of 3-hydroxy-3-methylglutaryl coenzyme A reductase in Trypanosoma brucei. Mol. Biochem. Parasitol. 69, 1:29-40.

Cortez, E, Stumbo, AC, Oliveira, M, Barbosa, HS, Carvalho, L, 2009: Statins inhibit Toxoplasma gondii multiplication in macrophages in vitro. Int. J. Antimicrob. Agen. 33, 185:e186. Davidson, MH, 2002: Rosuvastatin: A highly efficacious statin for the treatment of dyslipidaemia. Exp. Opin. Invest. Drugs 11, 1:125-41. Dieleman, LA, Palmen, MJ, Akol, H, Bloemena, E, Peña, AS, et al,1998: Chronic experimental colitis induced by dextran sulphate sodium (DSS) is characterized by Th1 \& Th2 cytokines. Clin. Exp. Immuno.114:385-91

Dinesh, N, Pallerla, DS, Kaur, PK, KishoreBabu, N, Singh, S, 2014: Exploring Leishmania donovani 3-hydroxy-3-methylglutaryl coenzyme A reductase, HMGR as a potential drug target by biochemical, biophysical and inhibition studies. Microb. Pathog. 66:e14-23.

Drury, RAB, Wallington, EA, 1980: Carleton's Histological Technique. $5^{\text {th }}$ ed. Oxford, New York, Toronto: Oxford University Press.

Giacometti, A, Cirioni, O, Barchiesi, F, Ancarani, F, Scalise, G, 2000: Activity of nitazoxanide alone and in combination with azithromycin and rifabutin against Cryptosporidium parv-um in cell culture. J. Antimicrob. Chemother. 45, 4:453-6.

Gomez, MA, Ausiello CM, Guarino A, Urbani F, Spagnuolo MI, et al, 1996: Severe, protracted intestinal cryptosporidiosis associated with interferon $\gamma$ deficiency: Pediatric case report.

Clin. Infect. Dis. 22, 5:848-50.

Grellier, P, Valentin, A, Millerioux, V, Schrevel, J, Rigomier, D, 1994: 3-Hydroxy-3- methylglutaryl coenzyme A reductase inhibitors lovastatin and simvastatin inhibit in vitro development of Plasmodium falciparum and Babesia divergens in human erythrocytes. Antimicrob. Agen. Chemother. 38:e1144-8.
Hayward, AR, Chmura, K, Cosyns, M, 2000: Interferon- $\gamma$ is required for innate immunity to Cryptosporidium parvum in mice. J. Infect. Dis. 182, 3:1001-4.

Hosking, BC, Watson, TG, Leathwick, DM, 1996: Multigeneric resistance to oxfendazole by nematodes in cattle. Vet Rec 138:67-8

Huwiler, A, Pfeilschifter J, 2009: Lipids as targets for novel anti-inflammatory therapies. Pharmacol. Therap. 124, 1:96-112.

Lacroix, S, Mancassola, R, Naciri, M, Laur ent, F, 2001: Cryptosporidium parvum-specific mucosal immune response in $\mathrm{C} 57 \mathrm{BL} / 6$ neonatal and gamma interferon-deficient mice: role of tumor necrosis factor alpha in protection. Infect. Immun. 69, 3:1635-42.

Li, X, Brasseur, P, Agname, P, Leméteil, D, Fennec, L, et al, 2003: Long-lasting anti-cryptosporidial activity of nitazoxanide in an immunosuppressed rat model. Folia Parasitol. 50:19-22.

Li, ZH, Ramakrishnan, S, Striepen, B, Moreno, SNJ, 2013: Toxoplasma gondii relies on both host and parasite isoprenoids and can be rendered sensitive to atorvastatin. PLoS. Path. 9, 10:e1003665.

McVay, CS, Rolfe, RD, 2000: In vitro and in vivo activities of nitazoxanide against Clostridium difficile. Antimicrob. Agen. Chemother. 44, 9:2254-8.

Mirza, H, Wu, Z, Teo, JD, Tan, KS, 2012: Statin pleiotropy prevents rho kinase-mediated intestinal epithelial barrier compromise induced by Blastocystis cysteine proteases. Cell Microbiol. 14:1474-84.

National Collaborating Centre for Primary Care, 2010: NICE Clinical Guideline 67: Lipid Modification: National Institute for Health and Clinical Excellence, London.

Nishikawa, Y, Ibrahim, HM, Kameyama, K, Shiga, I, Hiasa, J, et al, 2011: Host cholesterol synthesis contributes to growth of intracellular Toxoplasma gondii in macrophages. J. Vet. Med. Sci. Tokyo 73, 5:e633-9.

Paget, GE, Barnes, JM, 1964: Evaluation of drug activities. In: Laurence, DR Backarach, AL Eds. Pharmacometrics London \& New York: Academic Press

Pantenburg, B, Dann, SM, Wang, HC, Robinson, P, Castellanos, A, et al, 2008: Intestinal immune response to human Cryptosporidium $\mathrm{sp}$. infection. Infect. Immun. 76, 1:23-9.

Peat, J, Barton, B, 2005: Medical statistics: A 
guide to data analysis and critical appraisal. $1^{\text {st }}$ Ed. Oxford: Blackwell Publishing Ltd.

Penna-Coutinho, J, Cortopassi, WA, Oliveira, AA, Franca, TCC, Krettli, AU, 2011: Antimalarial activity of potential inhibitors of Plasmodium falciparum lactate dehydrogenase enzyme selected by docking studies. PLoS One 6, 7: e21237.

Pradines, B, Torrentino-Madamet, M, Fontaine, A, Henry, M, Baret, E, et al, 2007: Atorvastatin is 10 -fold more active in vitro than other statins against Plasmodium falciparum. Antimicrob. Agents Chemother. 51:e2654-5.

Reese, NC, Current, WL, Ernst, JV, Bailey, WS, 1982: Cryptosporidiosis of man and calf: a case report and results of experimental infections in mice and rats. Am. J. Trop. Med. Hyg. 31, 2:226-9.

Rehg, JE, Hancock, ML, Woodmansee, DB, 1988: Characterization of a dexamethasone treated rat model of cryptosporidial infection. J. Infect. Dis. 158:1406-7.

Rossignol, JF, Maisonneuve, H, 1984: Nitazoxanide in the treatment of Taenia saginata and Hymenolepis nana infections. Am. J. Trop. Med. Hyg. 33, 3:511-2.

Ryan, U, Hijjawi, N, Xiao, L, 2018: Foodborne cryptosporidiosis. Inter. J. Parasitol. 48:1-12.

Sateriale, A, Slapeta, J, Baptista, R, Engiles, JB, Gullicksrud, JA, et al, 2019: A genetically tractable, natural mouse model of cryptosporidiosis offers insights into host protective immunity. Cell Host Microbe 26, 5:e135-46.

Soliman, MFM, Ibrahim, MM, 2005: Antischistosomal action of atorvastatin alone and concurrently with medroxyprogesterone acetate on Schistosoma haematobium harbored in hamster, surface ultrastructure and parasitological study. Acta Trop. 93, 1:e1-9.

Sparks, H, Nair, G, Castellanos-Gonzalez, A, White, AC, 2015: Treatment of Cryptosporidium: what we know, gaps, and the way forward. Curr. Trop. Med. Rept. 2, 3:181-7

Taha, NM, Yousof, HSA, El-Sayed, SH, Younis, AI, Negm, MSI, 2017: Atorvastatin repur- posing for the treatment of cryptosporidiosis in experimentally immunosuppressed mice. Exp. Parasitol. 181: 57-69.

Theodos CM, Griffiths JK, D'onfro J, Fairfield A, Tzipori S, 1998: Efficacy of nitazoxanide against Cryptosporidium parvum in cell culture and in animal models. Antimicrob. Agen. Chemother. 42, 8:1959-65.

Widmer, G, Carmena, D, Kváč, M, Chalmers, RM, Kissinger JC, et al, 2020: Update on Cryptosporidium spp.: Highlights from $7^{\text {th }}$ Int. Giardia and Cryptosporidium Conf. Mise à jour sur Cryptosporidium spp. Parasite 27:14.

Wilke, G, Funkhouser, LJ, Wang, Y, Ravindran, S, Wang, Q, et al, 2019: A stem-cell-derived platform enables complete Cryptosporidium development in vitro and genetic tractability. Cell Host Microbe 26:123-34.

Wong, RPM, Davis, TME, 2009: Statins as potential antimalarial drugs, low relative potency and lack of synergy with conventional antimalarial drugs. Antimicrob. Agen. Chemother. 53, 5:2212e2214.

Xu, P, Widmer, G, Wang, Y, Ozaki, LS, Alves, JM, et al, 2004: The genome of Cryptospor idium hominis. Nature 431:1107e1112

Yi, T, Aao, R, Tang, PC, Wang, Y, Cuccaro, L, et al, 2008: Amelioration of human allograft arterial injury by atorvastatin or simvastatin correlates with reduction of interferon- $\gamma$ production by infiltrating T cells. Transplant. 186, 5:719-24. Zhang, Y, Lee, B, Thompson, M, Glass, R, Lee, R, et al, 2000: Lactulose-mannitol intestinal permeability test in children with diarrhea caused by rotavirus and Cryptosporidium: Diarrhea working group, Peru. J. Pediatr. Gastroenter ol. Nutr. 31, 1:16-21.

Zhou, Q, Liao, JK, 2009: Statins and cardiovascular diseases: from cholesterol lowering to pleiotropy. Curr. Pharm. Des. 15:467-78.

Zhou, T, Zhou, SH, Qi, SS, Shen, XQ, Zeng, G, et al, 2006: The effect of atorvastatin on serum myeloperoxidase and CRP levels in patients with acute coronary syndrome. Clin. Chim. Acta $368,1-2: 168-72$.

\section{Explanation of figures}

Fig.1: Experimental design of study

Fig.2: A- Oocyst count/ gm stool, comparison between each drug regimen in three time periods of prophylaxis, $1^{\text {st }} \& 2^{\text {nd }}$ booster therapeutic doses (T-test). B-IFN- $\gamma$ : Concentrations $(\mathrm{pg} / \mathrm{ml})$ in mice sera $(\mathrm{M} \pm \mathrm{SD})$ between each regimen in three time prophylaxis periods, $1^{\text {st }} \& 2^{\text {nd }}$ booster therapeutic doses by (T-test). C- Cryptosporidium ocyst in stool sample stained by M Z-N stain (x1500).

Fig. 3: $\mathrm{H} \& \mathrm{E}$ staining of Ileal mucosa for all groups $7^{\text {th }}, 14^{\text {th }} \& 21^{\text {st }}$ days PI. A-Normal control group showed normal ileal mucosa (x100). BATV Prophylaxis showed ileal mucosa with high grade dysplasia with frequent mitosis (x1000). C- NTZ prophylaxis showed ileal mucosa with high grade dysplasia with frequent mitosis (arrows). D- Combination (ATV \& NTZ) prophylaxis showed ileal mucosa with mild inflammation (arrows) and oocyst (x1000). E- Infected immunosuppressed control group (14 ${ }^{\text {th }}$ day PI) showed ileal mucosa with high grade dysplasia and oocysts surrounded by clear halo in brush border of ileal villi (x1000). F- ATV $1^{\text {st }}$ week treatment after prophylaxis group 
shows small intestinal submucosa infiltrated by moderate inflammatory cells (x1000). G- NTZ $1^{\text {st }}$ week treatment after prophylaxis showed oocysts (arrow) surrounded by clear halo in ileal villi brush border (x1000). H- Combined group $1^{\text {st }}$ week after prophylaxis showed ileal submucosa infiltrated by mild inflammatory cells (x100). I- Infected immunosuppressed control group (21 ${ }^{\text {st }}$ days PI) showed ileal mucosa with high grade dysplasia and two oocysts (arrows) surrounded by clear halo (x1000). J- ATV $2^{\text {nd }}$ week treatment after PX showed small intestine with lamina propria infiltrated by mild to moderate inflammatory cells (x1000). K- NTZ $2^{\text {nd }}$ week treatment after PX showed small intestine with submucosal infiltration by extensive number of inflammatory cells (x1000). L- Combined group $2^{\text {nd }}$ week treated group with ATV 40 after PX: showed ileal mucosa with mild inflammatory cells in lamina propria (x400).

Fig. 4: $\mathrm{H} \&$ E staining of gastric mucosa for all groups $7^{\text {th }}, 14^{\text {th }} \& 21^{\text {st }}$ days PI. A- Normal control group showed gastric mucosa with normal histology (x400). B- Infected control group showed gastric mucosa infected by multiple Cryptosporidium oocysts, (arrows) surrounded by clear halo (x1000). C- ATV prophylaxis showed gastric mucosa infected by oocysts, arrow surrounded by clear halo (x400). D- NTZ PX group showed gastric mucosa with low grade dysplasia with mitosis encircled (x400). E- Combined PX showed gastric mucosa with edema in lamina propria $(\mathrm{x} 400)$. F- ATV 1st week treatment after PX showed necrotic gastric mucosa with multiple oocysts, surrounded by clear halo (x400). G- NTZ $1^{\text {st }}$ week treatment after PX showed gastric mucosa with low grade dysplasia and oocysts arrow (x400). H- Combination 1 st week treatment after PX showed gastric mucosa with moderate inflammation lamina propria histology (x100). I- ATV $2^{\text {nd }}$ week treatment after PX showed gastric mucosa with normal histology with edema in muscle layer encircled (x400). J- NTZ $2^{\text {nd }}$ week after prophylaxis showed moderate dysplasia of gastric epithelium $(\mathrm{x} 1000)$. K- Combined group $2^{\text {nd }}$ week treatment after prophylaxis showed gastric mucosa with normal histology with edema in muscle layer encircled (x100).

Fig. 5: $\mathrm{H} \& \mathrm{E}$ staining of liver tissue for all groups $7^{\text {th }}, 14^{\text {th }} \& 21^{\text {st }}$ days PI. A- Normal hepatocytes arranged in cords, with normal sinusoids (x400). B- Infected control group showed liver tissue infected by Cryptosporidium oocysts showed portal tract expansion by inflammatory cellular infiltrate (black arrow) and bile duct proliferation (x400). C- ATV group after PX: Liver tissue showed moderate inflammation in portal tract (x100). D- NTZ prophylaxis group showed large cell dysplasia of liver tissue and focal necrosis (x400). E- Combination group after PX Liver tissue showed portal tract with moderate inflammation (x400). F- ATV $1^{\text {st }}$ week treated group after PX showed liver tissue infected by oocysts showed mild portal inflammation and cytoplasmic vacuolation (x100). G- NTZ $1^{\text {st }}$ week treatment after PX: liver showed dilated portal tract with severe inflammation $(\mathrm{x} 400)$. H- Combination $1^{\text {st }}$ week treated group after PX shows Liver tissue showing dilated sinusoids arrow $(\mathrm{x} 400)$. I- ATV $2^{\text {nd }}$ week treated group after PX: Liver tissue showed focal necrosis of hepatocytes encircled with large cell dysplasia (x100). J- NTZ $2^{\text {nd }}$ week treated group after PX: Liver tissue showed marked vacuolated cytoplasm encircled and moderate inflammation (x400). K- Combination $2^{\text {nd }}$ week treated group after PX: Liver tissue showed mild to moderate portal tract inflammation.

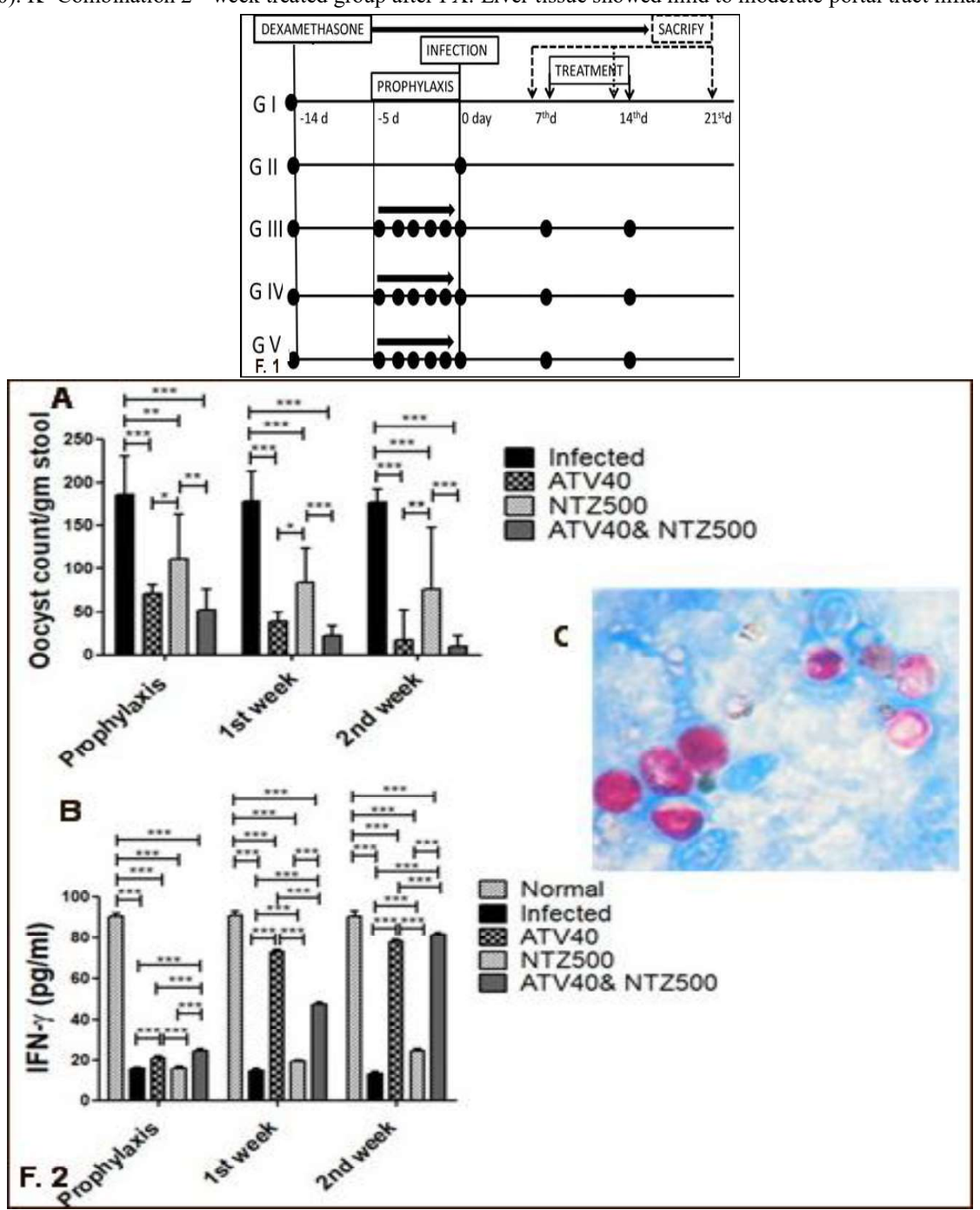



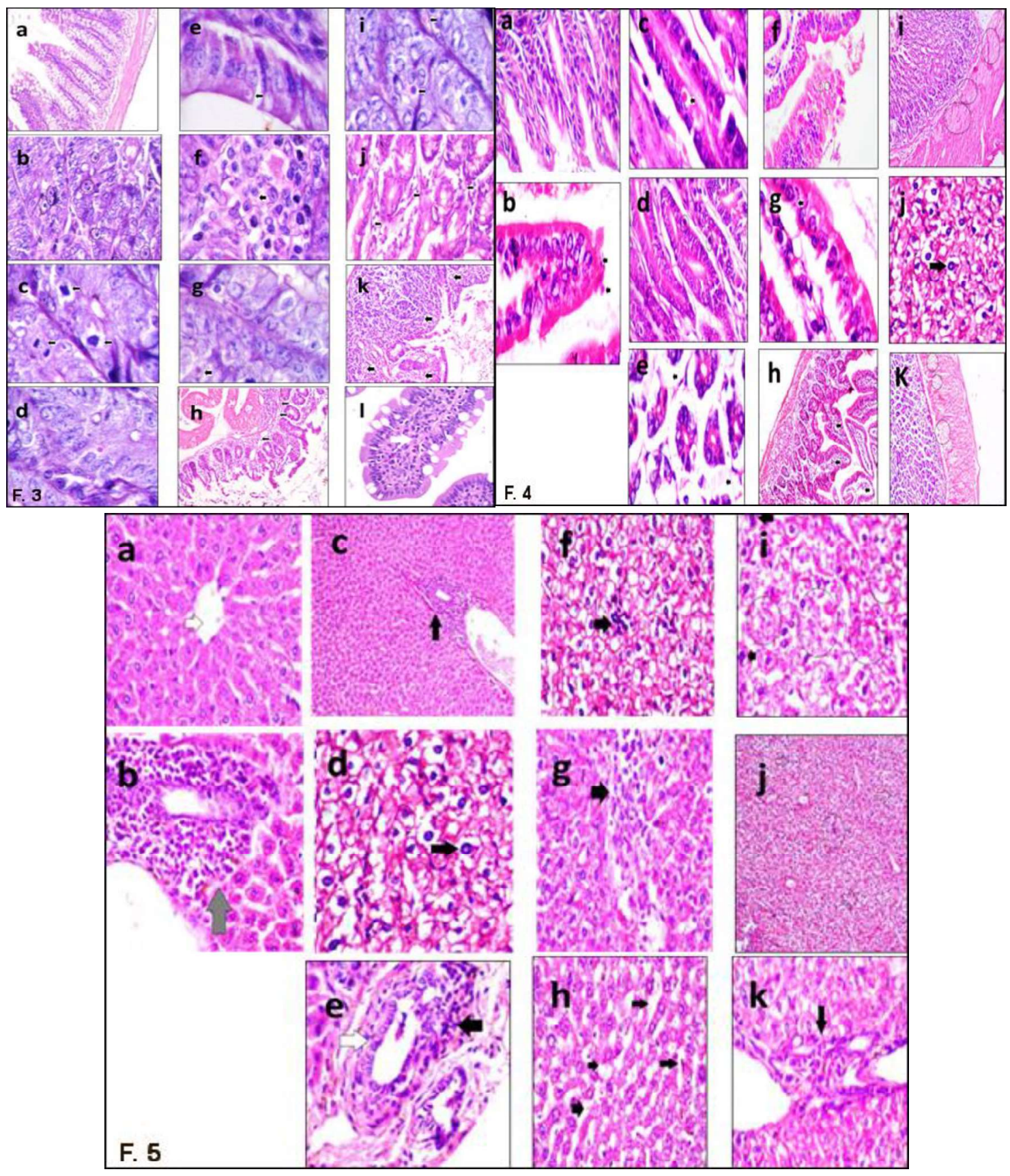